\title{
Comparative Study on Morphological, Physical and Mechanical Characteristics of L-PBF Based Alsi10mg Parts with Conventional Stir Casted Al- 10\%Sic Composites
}

\author{
M. Saravana Kumar ( $\nabla$ saravana312@gmail.com ) \\ Mount Zion College of Engineering and Technology https://orcid.org/0000-0001-8564-5905 \\ E. Mohan
}

Mount Zion College of Engineering and Technology

S. Robinson

Mount Zion College of Engineering and Technology

D. ThivyaPrasad

Mount Zion College of Engineering and Technology

\section{Research Article}

Keywords: stir casting, additive manufacturing, print orientation, porosity, fracture toughness, shear stress.

Posted Date: April 12th, 2021

DOl: https://doi.org/10.21203/rs.3.rs-246358/v1

License: (c) (1) This work is licensed under a Creative Commons Attribution 4.0 International License. Read Full License

Version of Record: A version of this preprint was published at Silicon on March 18th, 2021. See the published version at https://doi.org/10.1007/s12633-021-01065-9. 


\section{Abstract}

Stir casting plays a major role in production of Al-SiC10\% composites for aero space and automobile applications. However, obtaining the composites with homogenous distribution of the SiC particles, low porosity and without clustering of reinforcement particles were still a major problem faced by the research community. These kinds of casting defects were overcome by the Additive Manufacturing (AM) technology. In this research, AISi10Mg parts were manufactured by Laser-Powder Bed Fusion (LPBF) method, one of the AM techniques. The mechanical and morphological characteristics of AM samples were compared with the Stir Casted (SC) samples. The influence of print orientation on the mechanical properties was also evaluated. It was found that the AM samples printed along the XY directions shows $26.5 \%$ and $8.2 \%$ higher fracture toughness and shear strength than AM samples printed along the $Z$ directions. Both AM and SC samples were analyzed for the porosity\% using the Optical Microscope (OM). The result shows that the AM sample shows reduced porosity of $1.4 \%$. Mechanical testing such as tensile test, hardness test, fracture toughness test and double shear stress were carried out. The results obtained from the tensile test AM samples show $14.6 \%$ higher tensile strength than the SC samples, from the hardness test AM samples show 18.6\% higher hardness strength than the SC samples, from the fracture toughness test AM samples show $33.4 \%$ higher fracture toughness strength than the SC samples and from the double shear stress test prove that the AM samples show $24.6 \%$ higher shear stress than the SC samples. The outcome of this research, it was proved that additive manufactured AlSi10Mgsample shows enhanced mechanical and morphological properties when compared with the conventional stir casting process.

\section{Introduction}

In the recent years, AM plays a major role in high end applications such as biomedical, automobile and aerospace [1]. In the AM process, the materials were built up by the sintering of particles layer by layer [2]. It can build complex object with high geometry and also it can manufacture a component which was impossible in conventional manufacturing methods [3]. Mostly in the aerospace applications, AM is playing a significant role in weight reduction and increasing performance which in turn reduces cost of space missions [4]. However, it was necessary to analyze the inherent imperfection of this technology by evaluating the defects arising from the mechanical properties. Based on increased mechanical performance, aluminium alloys are used in the space industries due to their high strength to weight ratio and low cost [5]. The AlSi10mg was the commonly used alloy in the AM process, however the manufacturability through AM was more challenging when compared with the stainless steels and the titanium alloys [6].

Emilie et al carried out an investigation on mechanical and micro structural analysis of additively manufactured AISi10Mg and also analyzed the fatigue properties on the AISi10Mg build parts. From the results, it was observed that the building directions, heat treatment, platform temperature, surface finish and powder layer thickness also play a significant role in improving the mechanical performance [7]. Wen Hao Kan et al examined the effect of porosity percentage on the additive manufactured AlSi10Mg. It was 
clearly evident from the outcome that the sub optimal density shows an impact in the microstructure and the mechanical properties. It was also proved that even when the defects were not oriented properly, the toughness of the parts were improved [8]. Mulin Liu et al carried out the experimental investigation on the micro structural characteristics on the AlSi10Mg alloy manufactured based on selective laser sintering. From the analysis, it was observed that the fine eutectic Si particles were present around the melt pools. The effective microstructure was more evident in samples with higher inclination, which exhibits deviations in hardness values [9]. Biagio Palumbo et al adopted nested effect modeling based on ANOVA and design of experiments technique. The investigation of the influence of the different laser exposure strategies on the tensile properties of the AlSi $10 \mathrm{Mg}$ parts and also analyzed the various mechanical and physical properties. From the result it was obtained that optimized laser parameters were obtained for the improved mechanical properties of AlSi10Mg parts [10]. Michaela Fousová et al examined the impact of exposure temperature before the processing of AlSi10Mg alloy based on the selective laser sintering. The results show that for each exposure temperature there will be a significant impact in hardness values. From the TEM analysis, it was observed that the presence of nano precipitate helps to increase the yield strength of the alloy which subsequently decreases the elongation. From the result, it was proved that the operating temperature showed a significant impact in smooth operation of the additive manufacturing parts [11].Noriko Read et al examined the influence of various selective laser melting process parameters on the porosity on the AlSi10Mg alloy parts. From the result it was observed that the optimized process parameters shows reduced porosity with enhanced creep resistance than cast alloy [12].Lucia Denti et al evaluated the mechanical and morphological properties of the A357.0 based on the different orientation of the build parts. The result shows that the tensile and shear strength of the build parts were improved based on the optimized orientation [13].

Dey et al., investigated the influence of micro SiC addition to the aluminium matrix composites using stir casting process. Various weight fractions of $\mathrm{SiC}$ particles were incorporated to find out the effect of micro $\mathrm{SiC}$ on the mechanical properties. Fabrication was carried out by considering all the stir casting parameters constant. The results reveals that the mechanical properties and the tribological properties were increased by the addition of micro SiC particles [14]. Prabaharan et al., examined the characteristics of aluminium matrix composite when reinforced with $\mathrm{SiC}$ in different weight percentage using stir casting. The tribological behaviour was assessed by dry sliding wear at the different weight percentage of $\mathrm{SiC}$ in aluminium matrix. Thus, it was proved that the mechanical and tribological characterization can be increased by adding SiC [15]. Surya et al., investigated the tribological characteristics of aluminium matrix reinforced with $\mathrm{SiC}$ in different weight percentage using powder metallurgy. The study reveals that wear loss and coefficient of frictions are influenced by sliding distance, load and \% reinforcement. Thus, the effect of $\mathrm{SiC}$ on tribological characteristic influences the coefficient of friction of the aluminium matrix [16]. Karvaniset al investigated the effect of SiC particles on the aluminium matrix based on the mechanical properties. From the result it was observed that the presence of $\mathrm{SiC}$ content increases the tensile strength and the compression strength of the composites and also the presence of SiC particles makes the materials much harder [17]. ShahinSoltani et a/ investigated the influence of casting temperature and stirring periods on the $\mathrm{Al}-\mathrm{SiC} 3 \mathrm{wt} \%$ composites. From the result it was concluded that 
the reduced stirring speed helps for Al-SiC bonding interface and also observed that the higher processing temperature helps in improved incorporation of SiC particles [18]. John Victor Christy et al evaluated the effect of stir casting parameters on the microstructure and mechanical properties of the aluminium matrix composites. From the result it was observed that the compression strength, porosity and other mechanical properties were considerably increased by the optimized stir casting parameters [19]. Pradeepkumar et al examined the morphological and mechanical properties of the aluminium metal matrix composites by varying the compositions of the matrix and the reinforcements. From the outcome it shows that the hardness, abrasive wear and ultimate tensile strength were improved in aluminiumalumina metal matrix composites [20].

In this research LPBF, one of the additive manufacturing techniques was compared with the conventional stir casting process. AlSi10Mg alloy was chosen for Additive manufacturing using LPBF. Al-SiC 10\% composite samples were manufactured by stir casting process. Both AM and SC samples were comparatively analyzed for the microstructural and morphological analysis and also mechanical characterization. The Micro structural analysis helps to analyze the porosity\% and the distribution of the reinforcement particles in AM and SC samples. SEM analysis also helps to find the surface morphology of the AM and SC samples. The microstructural analysis reveals that the presence of micro pores gives high strength to weight ratio by enhancing all the mechanical properties. Physical properties were evaluated to find the role of density in both the AM and SC samples. Tensile test were carried out for both AM samples and SC samples using Universal Testing Machine. Form the tensile test, elongation \%, reduction in area \%, tensile strength (MPa) and yield strength (MPa) were compared between the AM and SC samples. Brinell hardness test were carried out to find out the maximum hardness between the AM and SC samples. The results from the hardness test shows that the AM samples exhibits $23.69 \%$ higher hardness when compared with the stir casted samples. Fracture toughness test and shear test was carried out for both AM and SC samples. The AM samples exhibits $50 \%$ of higher fracture toughness when compared with SC samples and also the AM samples shows $32.5 \%$ higher resistance to the crack propagation when compared with the SC samples. The results proves the enhanced mechanical properties of the AM samples.

\section{Materials And Methods}

\subsection{Chemical compositions}

For the Additive manufacturing using LPBF, AlSi10Mg alloy was chosen. The chemical compositions were shown in the Table.1. For the stir casting process, aluminum alloy (Al8011) was chosen as matrix and Silicon Carbide (SiC) was chosen as the reinforcement particles for this conventional manufacturing process [21]. Aluminum 8011 alloy primarily consist of $98 \%$ of aluminum with significant amount of bismuth, silicon, tin, ferrous, lead, copper, zinc, few traces of magnesium and titanium. Silicon carbide is a hard covalently reinforced material dominatingly created by the carbo thermal extracted from silica normally utilizing the Acheson process. So, SiC particles with 325 mesh was used as the reinforcement particles. Table.2. shows the chemical composition of aluminum / aluminum 8011 alloy. 


\subsection{Stir casting process}

Al-SiC $10 \%$ samples were manufactured by stir casting process. The stir casting process parameters were shown in the Table.3. At first, the furnace was heated up to $800^{\circ} \mathrm{C}$ and then Al-8011 aluminum alloy billets were placed inside the crucible. The working temperature of $750^{\circ} \mathrm{C}$ was made constant. Then the $\mathrm{SiC}$ reinforcement particles were introduced inside the molten aluminum melt. Stirring was carried out with $45^{\circ}$ blade angle for a holding time of 10 mins which was kept $40 \%$ from the base. Finally, the molten aluminum was poured into the mold to get the casted samples [22].

Table.1 Chemical composition of AlSi10Mg Alloy (Weight \%)

\begin{tabular}{|lccccc|}
\hline Elements & Minimum & Maximum & S1 & S2 & S3 \\
\hline Manganese-Mn & - & 0.45 & 0.040 & 0.040 & 0.040 \\
\hline Silicon-Si & 9.0 & 11.0 & 10.62 & 10.57 & 10.52 \\
\hline Nickel-Ni & - & 0.05 & 0.015 & 0.015 & 0.015 \\
\hline Copper-Cu & - & 0.05 & 0.019 & 0.021 & 0.021 \\
\hline Titanium-Ti & - & 0.15 & 0.012 & 0.012 & 0.012 \\
\hline Tin-Sn & - & 0.05 & $<0.01$ & $<0.01$ & $<0.01$ \\
\hline Zinc-Zn & - & 0.10 & $<0.01$ & $<0.01$ & $<0.01$ \\
\hline Lead-Pb & - & 0.15 & 0.011 & 0.011 & 0.011 \\
\hline Iron-Fe & - & 0.55 & 0.13 & 0.13 & 0.13 \\
\hline Magnesium-Mg & 0.20 & 0.45 & 0.32 & 0.33 & 0.32 \\
\hline Others-Each & - & 0.05 & $<0.05$ & $<0.05$ & $<0.05$ \\
\hline Others-Each & - & 0.05 & 0.046 & 0.033 & 0.023 \\
\hline Aluminium-Al & - & Balance & Balance & Balance & Balance \\
\hline
\end{tabular}

Table.2 Chemical Composition of Aluminum 8011 


\begin{tabular}{|lc|}
\hline Elements & Composition (\%) \\
\hline Silicon & 0.213 \\
\hline Iron & 0.40 \\
\hline Copper & 0.10 \\
\hline Manganese & 0.018 \\
\hline Magnesium & 0.10 \\
\hline Titanium & 0.009 \\
\hline Zinc & 0.210 \\
\hline Lead & 0.009 \\
\hline Tin & 0.030 \\
\hline Bismuth & 0.002 \\
\hline Zirconium & 0.002 \\
\hline Chromium & 0.002 \\
\hline Aluminum & 98.905 \\
\hline
\end{tabular}

Table.3 Stir Casting Process Parameters.

\begin{tabular}{|ll|}
\hline Working temperature & $750^{\circ} \mathrm{C}$ \\
\hline Capacity of the melting pot & $1 \mathrm{~kg}$ of Aluminum (max) \\
\hline Stirring speed & $250 \mathrm{rpm}$ \\
\hline Maximum operating temperature & $900^{\circ} \mathrm{C}$ \\
\hline Operating Voltage & $440 \mathrm{~V}, \mathrm{AC}$ three Phase $50 \mathrm{c} / \mathrm{s}$ \\
\hline Holding time & $10 \mathrm{mins}$ \\
\hline App. Power consumption & $4 \mathrm{KW}$ \\
\hline Impeller position & $40 \%$ from the base \\
\hline Preheating furnace Temperature & $800{ }^{\circ} \mathrm{C}$ \\
\hline Stirrer blade angle & $45^{\circ}$ \\
\hline Control & Automatic by microcontroller \\
\hline
\end{tabular}




\subsection{AM based Laser Powder Bed Fusion process}

AM specimens were manufactured by LPBF, with an EOS M280 system with the compressed air supply of $7,000 \mathrm{hPa} ; 20 \mathrm{~m}^{3} / \mathrm{h}, \mathrm{Yb}$ (Ytterbium) fibre laser with nominal power of $400 \mathrm{~W}$, diameter of laser beam at building area 100 - $500 \mu \mathrm{m}$. Fig.1 shows Metal Additive manufacturing EOS M280 system. As mentioned by the manufacturer, laser power of $370 \mathrm{~W}$, layer thickness of $30 \mu$ mscanning speed of $1300 \mathrm{~mm} / \mathrm{s}$ and hatching distance of $190 \mu \mathrm{m}$ were used as the processing parameters for LPBF [22]. It was make sure that all the AM samples were manufactured based on the same process parameters to analyze the micro structural and mechanical properties.

The LPBF method will provide a way to fabricate the specimens for investigations. The system involving dispenser unit caring aluminium alloy powder (AlSi10mg) with 15 micron which continuously supply the metal powder during the entire printing processes. The dispenser duct was specially designed to carry the aluminium alloy powder which has high material stability [23]. The dispenser unit was connected with strong build platforms which will helps to provide a space for the development of specimens for evaluation. The high sensitive re-coater will provide a way to material frameworks. The excess amount of powder material was collected in the collector unit called as Interpretable Properties Chain Module (IPCM).The process initiates with removing oxygen content presents in the printing chamber and maintain as $0.1 \%$ level. The inert gas preferably Argon is chosen to reduce the oxidization of sintering processes to create a stable printing condition by maintaining constant pressure, keeping out the impurities, reducing the powder climbing and control the thermal stresses [24].

The Electro optical system triggers the high intensity laser beam with the range of $600-700 \mathrm{~nm}$ wave length by providing $1 \mathrm{mw}$ laser radiation which will solidify the powder particles as per the geometrical dimensions fed in to the system already [25].The laser calibration will be done for every continuous cycles. The angular rotation of the laser dispensing system will have $45^{\circ}$ to $67^{\circ}$ fusion. The special filter $\mathrm{H} 13$ and F9 comes in to function for collecting the unused and climbing powdered molecules [26]. Before initialing the process, the necessary primary verification was done with the simulation. The specimens were primarily designed using the Solidworks modelling software and it was imported to Material Magic Data Preparation Software (MMDPS) for simulation and validating the entire process Design for Additive Manufacturing (DAM) [27]. Once the simulation process was successfully validated the same parameters as fed into the Electro Optical System Builder (EOS builder) [28]. Through the EOS builder the LPBF process method will be initiated.

\subsection{Micro structural analysis}

Fabricated samples were cut into specimen size of $10 \mathrm{~mm} \times 10 \mathrm{~mm} \times 10 \mathrm{~mm}$ using the Wire cut Electric Discharge Machining process (WEDM). The specimens were analyzed for their morphology using $\mathrm{OM}$ and SEM analysis. The specimens were etched and polished before the analysis of the OM and SEM 


\subsection{Porosity measurements}

The porosity percentage can be estimated by measuring the relative density of the specimen $(\mathrm{P} \%+\mathrm{RD}=$ 100). Relative density can be calculated by measuring the bulk density and dividing it by the theoretical density of the specimen. Bulk density can be measured using the Archimedes method. The theoretical density can be calculated employing the rule of mixtures. Part density of as built AlSi10Mg test samples tested as per ASTM B311 using the WEDM. The porosity in the specimens was determined using Eq. (1).

$P=1-(\rho$ experimental $/ \rho$ theoretical $) \times 100$

\subsection{Mechanical characterizations}

Tensile test performed for XY and Z direction test samples as per ASTM E8/E8M specification. The same ASTM standards were specified on both AM and SC samples. Universal Testing Machine (H5OKL, Tinios Olsen Computerized model) was used for finding tensile properties (UTS, YS and \% El) for the cast specimens and AM build parts. Hardness of as build AlSi10Mg test samples tested as per ASTM E10. Brinell macro- hardness tester (HR-320, Mitu Toyo South Asia Pvt Ltd), was used for finding the hardness values for both $\mathrm{AM}$ and $\mathrm{SC}$ samples. Fracture toughness for $\mathrm{XY}$ and $\mathrm{Z}$ directions as built test samples tested as per ASTM E399 (Fig 2(b)). Materials Testing System (MTS 810) with 250KN load was used to the find the fracture toughness of the samples. Shear strength for $X Y$ and $Z$ directions as built test samples were fabricated as per ASTM E769 (Fig 2(a)). Double shear stress in Universal Testing Machine (H5OKL, Tinios Olsen Computerized model) was used to find the shear strength of the AM and SC samples.

\section{Results And Discussion}

\subsection{Micro structural analysis}

Fig. 3 shows the optical micrograph of the AM samples along the $Z$ direction and $X Y$ direction. From the microstructure of the SC samples (Fig.4) shows the distribution of the SiC reinforcement particles and also few porosities with some clustering of $\mathrm{SiC}$ particles were evident. This kind of defects formed during the solidification process. This was due to the entrapment of hydrogen gas during the solidification process. The wettability between the matrix and the reinforcement was also evident from the OM images. This was mainly due to the pre-heating of reinforcement particles. The uniform distribution of the reinforcement particles was the result from the effective stir casting parameters [29]. From the micrograph of AM samples, the presences of micro pores were evident which was considered to be one of the advantages of the AM samples. In the Fig.3 (a) shows the sintering of particles along the $Z$ directions. Few micro pores are observed in this direction which was due to the particles entrapment due to the gas expansion. The sintering of particles along the XY directions also shows few micro pores [30]. The few micro pores with circular shaped eutectic silicon phase mixture will helps to bond the materials which 
resist the deformation movements. Hence the presence of the pores will considered as one of the advantages in the AM samples. Fig. 5 shows the SEM images of the AM samples at 50X and 100X. From the SEM images of the AM samples, it was concluded that the surface finish was poor when compared with the SEM images of the SC samples in Fig.6. This was mainly due to the sintering effect caused by the laser which leads to the fusion of the particles which eventually makes the surface rougher when compared with the SC samples. In the fabrication of the SC samples, the molten metal was poured in the mold, so the surface of the casted specimen will have good surface finish when compared to the AM samples [31]. Thus, the AM samples definitely requires a post processing operations to achieve a good surface finish.

\subsection{Physical properties}

Fig.7 shows the comparison of the porosity of the AM samples and the SC samples. It was observed that the SC samples exhibits $66 \%$ higher porosity than the AM samples. This was due to the presence of reinforcement in the SC samples which creates sites for the nucleation of the new grains as well as pores. So this was the reason that the pure matrix materials always exhibit lower porosity percentage than the reinforced materials. It was well know that the porosity of the particle reinforced composites was much higher than the pure alloy [32]. Mostly porosity in the SC samples arises from the matrix shrinkage during the time of solidification and also by the gas entrapment which eventually affects the properties of the materials. At the time of solidification process, entrapment of hydrogen gas takes place which leads to the porosity in the casted samples [33]. The porosity of the stir casted samples can be reduced by increasing the working temperature because gas entrapment occurs during the stirring of molten matrix. On the comparison of density, it was obtained that the experimental density was close to theoretical density. The presence of micro pores in the additive manufactured AISi!)Mg samples was due to the presence of Silicon content which leads to the high nucleation sites. So the occurrence of micro pores was higher when compared to the SC samples [34]. The presence of micro pores was higher in the AM samples. The strength to weight ratio was increased due to the high concentration of the circular shaped eutectic silicon phase mixture. The presence of circular shaped eutectic silicon phase mixture will restrict the dislocation movements. It was evident that the presence of low porosity which act as the empty space will also give rise to the enhancement of the strength of the materials [35]. So, porosity of the stir cased sample is much higher than the 3D printed sample. In this comparative study, the porosity results were proved by the optical micrographs.

\subsection{Mechanical properties}

\subsubsection{Tensile test}

Fig.8 shows the comparison of the tensile strength of the L-PBF based AlSi10mg with the stir casted AlSiC10\%. From the result it was obtained that the AM samples exhibits $28.6 \%$ higher tensile strength when compared with the stir casted samples. The sample printed in the $Z$ direction (Fig.5) experienced higher tensile strength of $421 \mathrm{MPa}$. The sintering action along the $Z$ direction with the layer thickness of $30 \mu \mathrm{m}$ was the main reason for the higher tensile strength [36]. The sample printed in the XY-direction also 
shows $17 \%$ higher tensile strength than the stir casted sample. The direction of the sintering of particles along the $\mathrm{Z}$ direction was perpendicular to the direction of the applied tensile force which resist the dislocation moments and finally led to the increased tensile strength [37]. The propagation of the cracks which passes through the grain boundary of the SiC particles was the main reason for the lower tensile strength of the stir casted samples when compared with AM samples.

Fig. 9 shows the comparison of the yield strength of the AM samples with the stir casted samples. From the result it was observed that the AM samples along the $X Y$ directions exhibits more yield strength of $11.5 \%$ than the samples prepared along the $Z$ directions. This was mainly due the sintering of the particles along the $X Y$ direction which resist the dislocation movements. If the bonding along the $Z$ direction was perpendicular to the direction of the applied tensile force then the propagation of cracks will easily pass through the sintered particles which leads to the decreases the yield strength in the AM samples along $Z$ direction [38]. This was the reason for lower yield strength of the sample fabricated along the $Z$ direction when compared with the sample fabricated along the $X Y$ direction. The result also shows SC Al-SiC10\% samples shows 222MPa of yield strength which was lower when compared with the AM AISi10mg samples. In the stir casted samples, the dislocation moments will arise from the dendrite arms and also in the boundary region of the SiC particles. The reason lies behind the distribution of the $\mathrm{SiC}$ particles which reduces the yield strength of the stir casted samples.

Fig.10 shows the comparison of elongation percentage of the AM samples with the stir casted samples. The result shows that the SC sample shows $27.1 \%$ of more elongation when compared with the AM samples this was mainly due to the role of aluminium- silicon carbide bonding in the stir casted samples. The elongation was mainly due to the ductile nature of Aluminium which will be evident during the action of external loads [39]. Even though the presence of $\mathrm{SiC}$ particles will restrict the elongation movements, SC samples shows $27.1 \%$ higher elongating when compared to the AM samples. It was evident that the ultimate tensile strength increases with the decrease in the elongation percentage [40]. During the application of the external load, it was observed that the AM samples along the XY directions shows $89.9 \%$ more elongation when compared with the AM samples along the $Z$ directions. This was due to the fact that the sintering action along the $Z$ directions will hold the particles together and form a strong bonding which reduces the elongation moments.

Fig. 11 shows the comparison of the reduction in area of the AM sample with the SC samples. The elongation \% of the samples was directly proportional to the reduction area \% of the samples. It was evident that the SC samples shows $73.7 \%$ more reduction in area when compared with the AM samples. The ductile behavior of aluminium presence in the SC samples influences the elongation of the samples which consecutively leads to the more reduction in area when compared with the AM samples [41]. It was observed that the AM samples printed along the $\mathrm{XY}$ direction shows higher reduction in area when compared with the samples printed along $Z$ direction. The bonding will be week if the force was applied along the $Z$ directions. So this was the reason for the lower reduction in area\% in AM samples printed along the $Z$ directions [42]. The samples printed along the $Z$ directions exhibits maximum tensile strength 
of $421 \mathrm{MPa}$ which was the main reason for the lower reduction area \% of the samples when compared with the samples printed in XY direction and SC samples.

\subsubsection{Hardness test}

Fig.12 shows the hardness comparison of the AM samples with the SC samples. It was evident that the AM sample reveals $23.69 \%$ higher hardness when compared with the SC samples. The samples printed along the $X Y$ directions and $Z$ direction shows more or less same harness of $102 \mathrm{HBW}$. In the AM samples, the fusion of one layer of AISi particles over another layer makes the samples harder when compared with SC samples. The reason lies behind the hardness of the AM samples was the sintering of particles will makes the strong bond between the Al - Si and it will restrict the indentation effect more when compares with the SC samples [43]. The deviations of hardness values were observed in the SC samples. This was mainly due to the distribution of SiC particles [44].

\subsubsection{Fracture toughness test}

Fig.13 shows the comparison of the fracture toughness of the AM samples with the SC samples. The AM samples along the $X Y$ directions exhibits $50 \%$ higher resistance to the crack propagation when compared with the SC samples. It was evident that the AM samples printed along the XY directions creates more resistance to the propagation of cracks during the higher stress intensity. This was due to direction of propagation of the cracks was perpendicular to the direction of the fusion of particles along the $X Y$ directions [45]. In the AM samples printed along the $Z$ direction, the direction of the fusion of the particles was parallel to the direction of propagation of the cracks which led to the higher crack propagation due to the higher stress intensity. So, this was the reason for higher fracture toughness value of 31.99 $\mathrm{MPam}^{1 / 2}$ for the samples printed along the $X Y$ directions. The stir casted samples shows $50 \%$ of lower fracture toughness when compared with AM samples printed along the $X Y$ directions. The due to the stress intensity, the propagation of cracks along the grain boundaries of the SiC particles makes the samples weaker when compare to the AM samples [46].

\subsubsection{Shear strength test}

Fig.14 shows the comparison of the shear strength of the AM samples with the SC samples. The AM sample along the $X Y$ directions reveals $32.55 \%$ higher shear strength than the stir casted samples. It was observed that the AM samples printed along the $X Y$ directions shows more resistance to the shear force, this was mainly due to the direction of the fusion of the particles was perpendicular to the action of the applied force [47]. But in the samples printed along the $\mathrm{Z}$ directions, the direction of the shear force is parallel to the direction of the fusion of the particle. So this was the main reason for the higher shear strength along the $X Y$ directions and lower shear strength along the $Z$ direction [48]. In the stir casted sample, during the action of shear force, the propagation of cracks arises from the voids and travel through the grain boundaries of the SiC particles and propagate throughout the samples [49]. So, this was the reason behind the lower shear strength of $162 \mathrm{MPa}$ in stir casted samples when compared with 
the AM samples. Table 4 shows the comparison table for mechanical characterization of AM samples and SC samples

Table.4 Comparison table for mechanical characterization of AM samples and SC samples

\begin{tabular}{|c|c|c|c|}
\hline \multirow[t]{2}{*}{ Mechanical properties } & \multicolumn{2}{|c|}{ AM samples } & \multirow[t]{2}{*}{ SC samples } \\
\hline & XY-Directions & Z-Directions & \\
\hline Tensile strength in $\mathrm{MPa}$ & 383.667 & 421.667 & 327.667 \\
\hline Yield strength in $\mathrm{MPa}$ & 247.667 & 239 & 222 \\
\hline Elongation in \% & 9.833 & 5.176 & 12.5 \\
\hline Reduction in area (\%) & 13.53 & 8.763 & 23.513 \\
\hline Hardness in BHW & 102.667 & 101 & 83 \\
\hline Fractural toughness in $\mathrm{MPam}^{1 / 2}$ & 31.99 & 23.49 & 21.29 \\
\hline Shear strength in $\mathrm{MPa}$ & 215.451 & 197.633 & 162.532 \\
\hline
\end{tabular}

\section{Conclusion}

Experimental investigations were carried out for the effective manufacturing process. AM samples were manufactured by L-PBF, one of the additive manufacturing techniques and SC samples were manufactured by the conventional stir casting process. The manufactured samples were tested for their mechanical performance. The following conclusions were made.

- Micro pores were evident in the AM samples. The presence of micro pores gives high strength to weight ratio by enhancing all the mechanical properties.

- The presence of high concentration of the circular shaped eutectic silicon phase mixture will resist the dislocation movements in the AM samples.

- From the result of the tensile test, the AM sample printed in the Z-direction shows $28.6 \%$ higher tensile strength than the stir casted sample. The sample printed in the $Z$ direction experienced higher tensile strength of $421 \mathrm{MPa}$. 
- AM samples exhibits $23.69 \%$ higher hardness when compared with the SC samples. The samples printed along the $X Y$ directions and $Z$ direction shows more or less same harness of $102 \mathrm{HBW}$.

- AM samples printed along the $X Y$ directions shows $50 \%$ higher resistance to the crack propagation when compared with the SC samples. Higher fracture toughness value of $31.99 \mathrm{MPam}^{1 / 2}$ was obtained for the samples printed along the $X Y$ directions.

- AM sample printed along the XY directions shows $32.55 \%$ higher shear strength than the SC samples. Higher shear stress value of $215.45 \mathrm{MPa}$ was obtained for the samples printed along the $\mathrm{XY}$ directions.

\section{Declarations}

\section{Author contributions:}

M.Saravana Kumar: Conceptualization, Methodology, Investigation, E.Mohan - review \& editing, Project administration, S.Robinson - review \& editing, Supervision, D.ThivyaPrasad- review \& editing.

\section{Conflict of Interest:}

The authors have no conflicts of interest to declare that are relevant to the content of this article.

\section{Availability of data and materials:}

The raw/processed data required to reproduce these findings cannot be shared at this time as the data also forms part of an ongoing study.

\section{Consent to Participate:}

This article does not contain any studies with human participants performed by any of the authors.

\section{Consent to Publish:}

The authors provide their consent to publish this work in Silicon

\section{Compliance with Ethical Standards:}

\section{Ethical approval:}

This article does not contain any studies with human participants or animals performed by any of the authors.

\section{Funding statement:}

The authors did not receive support from any organization for the submitted work. 
Authors sincerely thanks to Mount Zion College of Engineering and Technology, Pudukkottai, Tamil Nadu, India for providing the facilities for this research work.

\section{References}

1. Salmi, A., Piscopo, G., Atzeni, E., Minetola, P., andluliano, L. (2018). On the effect of part orientation on stress distribution in AlSi10Mg specimens fabricated by laser powder bed fusion ( $\mathrm{L}$ PBF). Procedia CIRP, 67, 191-196.

2. Riemer, A., \& Richard, H. A. (2016). Crack propagation in additive manufactured materials and structures. Procedia Structural Integrity, 2, 1229-1236.

3. Almonti, D., Baiocco, G., Tagliaferri, V., \&Ucciardello, N. (2020). Design and Mechanical Characterization of Voronoi Structures Manufactured by Indirect Additive Manufacturing. Materials, 13(5), 1085.

4. Casati, R., Hamidi Nasab, M., Coduri, M., Tirelli, V., \&Vedani, M. (2018). Effects of platform pre-heating and thermal-treatment strategies on properties of AlSi10Mg alloy processed by selective laser melting. Metals, 8(11), 954.

5. Han, Q., Gu, H., Soe, S., Setchi, R., Lacan, F., \& Hill, J. (2018). Manufacturability of AlSi10Mg overhang structures fabricated by laser powder bed fusion. Materials \& Design, 160, 1080-1095.

6. Yu, T., Hyer, H., Sohn, Y., Bai, Y., \& Wu, D. (2019). Structure-property relationship in high strength and lightweight AlSi10Mgmicrolattices fabricated by selective laser melting. Materials \& Design, 182, 108062.

7. Beevers, E., Brandão, A. D., Gumpinger, J., Gschweitl, M., Seyfert, C., Hofbauer, P., ... \&Ghidini, T. (2018). Fatigue properties and material characteristics of additively manufactured AlSi10Mg-Effect of the contour parameter on the microstructure, density, residual stress, roughness and mechanical properties. International Journal of Fatigue, 117, 148-162.

8. Kan, W. H., Nadot, Y., Foley, M., Ridosz, L., Proust, G., \& Cairney, J. M. (2019). Factors that affect the properties of additively-manufactured AlSi10Mg: Porosity versus microstructure. Additive Manufacturing, 29, 100805.

9. Liu, M., Takata, N., Suzuki, A., \&Kobashi, M. (2018). Microstructural characterization of cellular AlSi10Mg alloy fabricated by selective laser melting. Materials \& Design, 157, 478-491.

10. Palumbo, B., Del Re, F., Martorelli, M., Lanzotti, A., \&Corrado, P. (2017). Tensile properties characterization of AlSi10Mg parts produced by direct metal laser sintering via nested effects modeling. Materials, 10(2), 144.

11. Fousová, M., Dvorský, D., Michalcová, A., \&Vojtěch, D. (2018). Changes in the microstructure and mechanical properties of additively manufactured AISi10Mg alloy after exposure to elevated temperatures. Materials Characterization, 137, 119-126.

12. Read, N., Wang, W., Essa, K., \&Attallah, M. M. (2015). Selective laser melting of AlSi10Mg alloy: Process optimisation and mechanical properties development. Materials \& Design (1980-2015), 65, 
417-424.

13. Denti, L. (2018). Additive manufactured A357. 0 samples using the laser powder bed fusion technique: Shear and tensile performance. Metals, 8(9), 670.

14. Dey, D., Bhowmik, A., \& Biswas, A. (2020). Effect of SiC content on mechanical and tribological properties of Al2024-SiC composites. Silicon, 1-11.

15. Prabaharan, T. (2020). Mechanical and Tribological Characterization of Stir Cast AA6061 T6-SiC Composite. Silicon, 1-8.

16. Surya, M. S., \& Prasanthi, G. (2021). Effect of SiC Weight Percentage on Tribological Characteristics of Al7075/SiC Composites. Silicon, 1-10

17. Karvanis, K., Fasnakis, D., Maropoulos, A., \& Papanikolaou, S. (2016, November). Production and mechanical properties of Al-SiC metal matrix composites. In IOP Conference Series: Materials Science and Engineering. IOP Publishing, 161, 012070.

18. Soltani, S., Khosroshahi, R. A., Mousavian, R. T., Jiang, Z. Y., Boostani, A. F., \&Brabazon, D. (2017). Stir casting process for manufacture of Al-SiC composites. Rare Metals, 36(7), 581-590.

19. Christy, J. V., Arunachalam, R., Mourad, A. H. I., Krishnan, P. K., Piya, S., \& Al-Maharbi, M. (2020). Processing, Properties, and Microstructure of Recycled Aluminum Alloy Composites Produced Through an Optimized Stir and Squeeze Casting Processes. Journal of Manufacturing Processes, 59, 287-301.

20. Krishnan, P. K., Christy, J. V., Arunachalam, R., Mourad, A. H. I., Muraliraja, R., Al-Maharbi, M., ... \& Chandra, M. M. (2019). Production of aluminum alloy-based metal matrix composites using scrap aluminum alloy and waste materials: Influence on microstructure and mechanical properties. Journal of Alloys and Compounds, 784, 1047-1061.

21. Kumar, S., \&Vasumathi, M. (2020). Applying visualization techniques to study the fluid flow pattern and the particle distribution in the casting of metal matrix composites. Journal of Manufacturing Processes, 58, 668-676.

22. Saravana kumar., Begum, S. R., \&Vasumathi, M.(2019) Influence of stir casting parameters on particle distribution in metal matrix composites using stir casting process. Materials Research Express, 6(10), 1065d4.

23. Casati, R., Nasab, M. H., \&Vedani, M. (2018). Effect of Different Heat Treatment Routes on Microstructure and Mechanical Properties of AISi7Mg, AISi10Mg and Al-Mg-Zr-Sc Alloys Produced by Selective Laser Melting. In Euro PM2018 Congress \& Exhibition(pp. 1-5).

24. Girelli, L., Tocci, M., Gelfi, M., \& Pola, A. (2019). Study of heat treatment parameters for additively manufactured AISi10Mg in comparison with corresponding cast alloy. Materials Science and Engineering: $A$, 739, 317-328.

25. Gouveia, R. M., Silva, F. J., Atzeni, E., Sormaz, D., Alves, J. L., \& Pereira, A. B. (2020). Effect of Scan Strategies and Use of Support Structures on Surface Quality and Hardness of L-PBF AISi10Mg Parts. Materials, 13(10), 2248. 
26. Somireddy, M., \&Czekanski, A. (2017). Mechanical characterization of additively manufactured parts by FE modeling of mesostructure. Journal of Manufacturing and Materials Processing, 1(2), 18.

27. Leary, M., Maconachie, T., Sarker, A., Faruque, O., \& Brandt, M. (2019). Mechanical and thermal characterisation of AlSi10MgSLM block support structures. Materials \& Design, 183, 108138.

28. Maamoun, A. H., Xue, Y. F., Elbestawi, M. A., \& Veldhuis, S. C. (2019). The effect of selective laser melting process parameters on the microstructure and mechanical properties of Al6061 and AlSi10Mg alloys. Materials, 12(1), 12.

29. Zhang, C., Zhu, H., Qi, Y., \& Zeng, X. (2019). The Effect of Annealing on Microstructure and Mechanical Properties of Selective Laser Melting AISi10Mg. In IOP Conference Series: Materials Science and Engineering, 538, 012023.

30. Begum, S. R., Kumar, M. S., Pruncu, C. I., Vasumathi, M., \& Harikrishnan, P. (2021). Optimization and fabrication of customized scaffold using additive manufacturing to match the property of human bone. Journal of Materials Engineering and Performance, 1-12

31. Kumar, M. S., Pruncu, C. I., Harikrishnan, P., Begum, S. R., \& Vasumathi, M. (2021). Experimental investigation of in-homogeneity in particle distribution during the processing of metal matrix composites. Silicon, 1-13.

32. Rajesh, A., \& Santosh, D. (2017). Mechanical properties of Al-SiC metal matrix composites fabricated by stir casting route. Research Medical Engineering Science, 2(6), 1-6.

33. Akinwamide, S. O., Lemika, S. M., \& Abiodun, B. (2019). Study of microstructural and mechanical properties of stir cast Al (SiC-Mg-TiFe) composite. Fluid Dynamics \& Materials Processing, 15(1), 1526.

34. Bhaskar, S., Kumar, M., \& Patnaik, A. (2019). Mechanical and Tribological overview of ceramic particulates reinforced aluminium alloy composites. REVIEWS ON ADVANCED MATERIALS SCIENCE, 58(1), 280-294.

35. Wang, P., Lei, H., Zhu, X., Chen, H., \& Fang, D. (2019). Influence of manufacturing geometric defects on the mechanical properties of AlSi10Mg alloy fabricated by selective laser melting. Journal of Alloys and Compounds, 789, 852-859.

36. Yan, C., Hao, L., Hussein, A., Bubb, S. L., Young, P., \&Raymont, D. (2014). Evaluation of light-weight AlSi10Mg periodic cellular lattice structures fabricated via direct metal laser sintering. Journal of Materials Processing Technology, 214(4), 856-864.

37. Beretta, S., Gargourimotlagh, M., Foletti, S., du Plessis, A., \& Riccio, M. (2020). Fatigue strength assessment of "as built" AlSi10Mg manufactured by SLM with different build orientations. International Journal of Fatigue, 139, 105737.

38. AlRedha, S., Shterenlikht, A., Mostafavi, M., Van Gelderen, D., Lopez-Botello, O. E., Reyes, L. A., ... \& Garza, C. (2020). Effect of build orientation on fracture behaviour of AlSi10Mg produced by selective laser melting. Rapid Prototyping Journal.

39. Subbiah, R., Bensingh, J., Kader, A., \& Nayak, S. (2020). Influence of printing parameters on structures, mechanical properties and surface characterization of aluminium alloy manufactured 
using selective laser melting. The International Journal of Advanced Manufacturing Technology, 106(11), 5137-5147.

40. Alghamdi, F., Song, X., Hadadzadeh, A., Shalchi-Amirkhiz, B., Mohammadi, M., \& Haghshenas, M. (2020). Post heat treatment of additive manufactured AlSi10Mg: On silicon morphology, texture and small-scale properties. Materials Science and Engineering: A, 783, 139296.

41. Yaghobizadeh, O., Baharvandi, H. R., Ahmadi, A. R., \& Aghaei, E. (2019). Development of the properties of $\mathrm{Al} / \mathrm{SiC}$ nano-composite fabricated by stir cast method by means of coating $\mathrm{SiC}$ particles with Al. Silicon, 11(2), 643-649.

42. Sanjari, M., Hadadzadeh, A., Pirgazi, H., Shahriari, A., Amirkhiz, B. S., Kestens, L. A., \& Mohammadi, M. (2020). Selective laser melted stainless steel CX: Role of built orientation on microstructure and micro-mechanical properties. Materials Science and Engineering: A, 786, 139365.

43. Del Re, F., Scherillo, F., Contaldi, V., Palumbo, B., Squillace, A., Corrado, P., \& Di Petta, P. (2019). Mechanical properties characterisation of AlSi10Mg parts produced by laser powder bed fusion additive manufacturing. International Journal of Materials Research, 110(5), 436-446.

44. Kumar, M. S., Begum, S. R., Pruncu, C. I., \& Asl, M. S. (2021). Role of homogeneous distribution of SiC reinforcement on the characteristics of stir casted Al-SiC composites. Journal of Alloys and Compounds, 159250.

45. Hartunian, P., \& Eshraghi, M. (2018). Effect of build orientation on the microstructure and mechanical properties of selective laser-melted Ti-6Al-4V alloy. Journal of Manufacturing and Materials Processing, 2(4), 69.

46. Premnath, A. (2020). Optimization of the process parameters on the mechanical and wear properties of Al-SiC nano-composites fabricated by friction stir processing using desirability approach. Silicon, 12(3), 665-675.

47. Ponnusamy, P., Rahman Rashid, R. A., Masood, S. H., Ruan, D., \& Palanisamy, S. (2020). Mechanical Properties of SLM-Printed Aluminium Alloys: A Review. Materials, 13(19), 4301.

48. Dong, M., Zhou, W., Kamata, K., \& Nomura, N. (2020). Microstructure and mechanical property of graphene oxide/AlSi10Mg composites fabricated by laser additive manufacturing. Materials Characterization, 170, 110678.

49. Kumar, P. V., Jebakani, D., Velmurugan, C., \& Senthilkumar, V. (2021). Effect of SiC on Mechanical and Microstructural Characteristics of Al Based Functionally Graded Material. Silicon, 1-6.

\section{Figures}



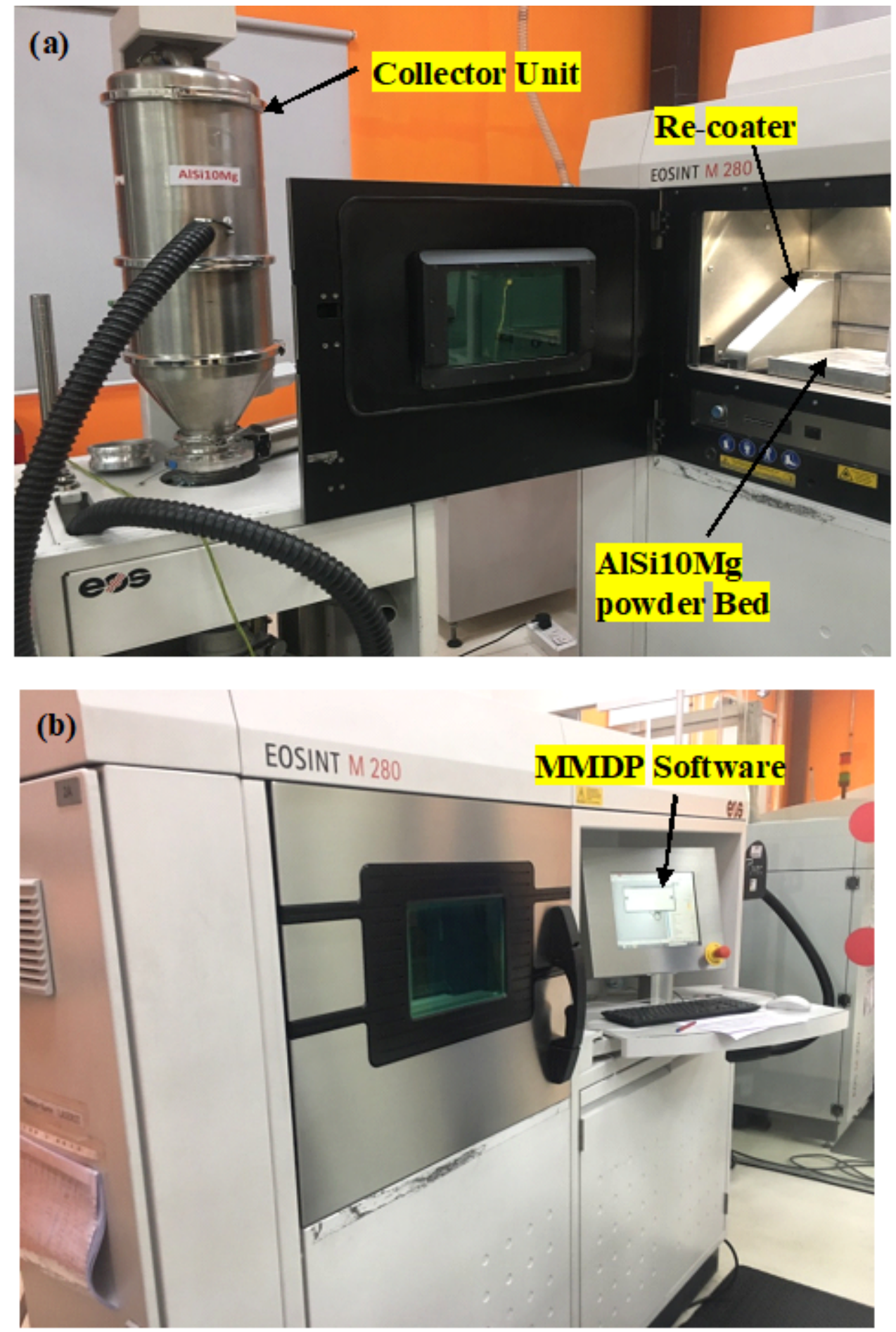

Figure 1

Metal Additive manufacturing EOS M280 system (a) Collector unit (b) MMDP software 
(a)

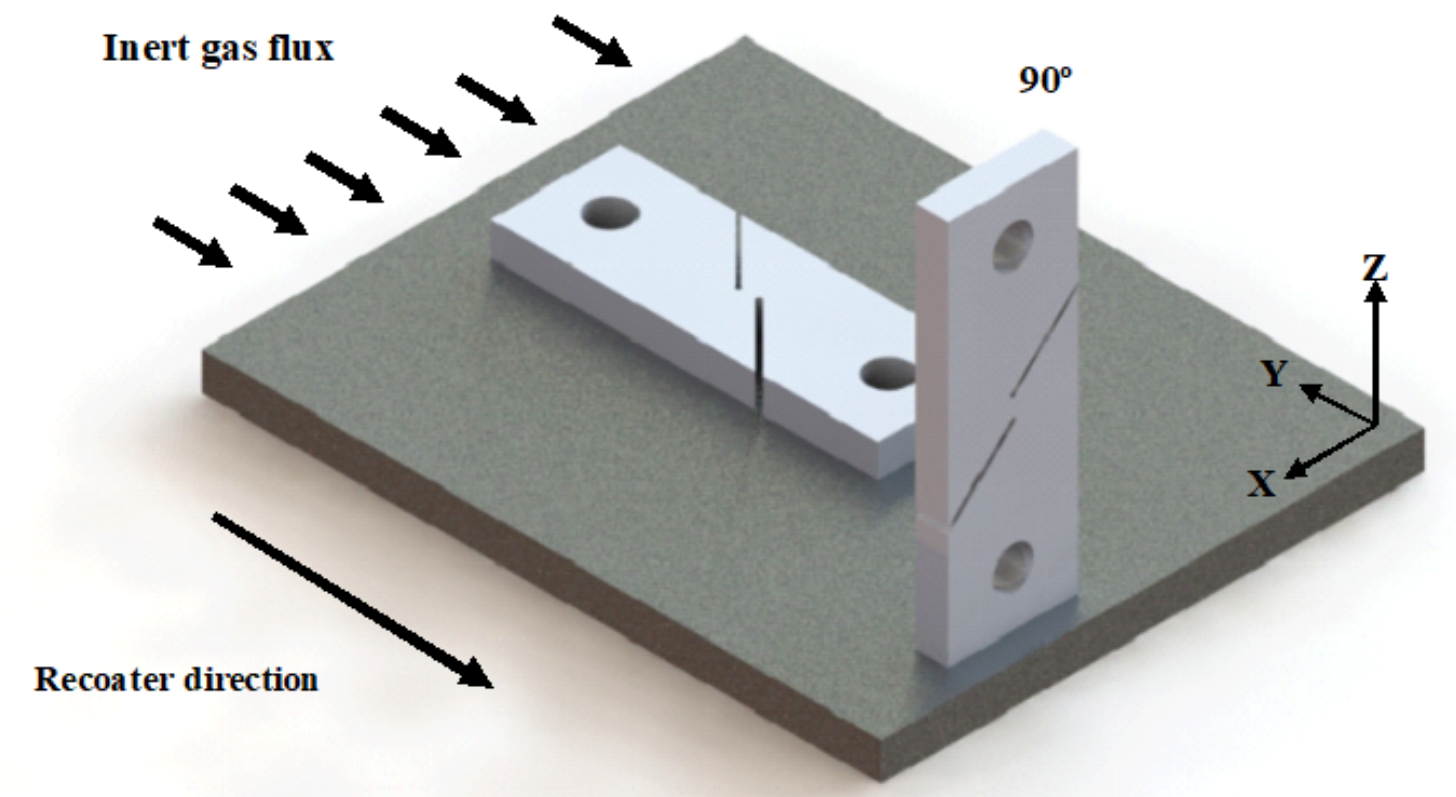

(b)

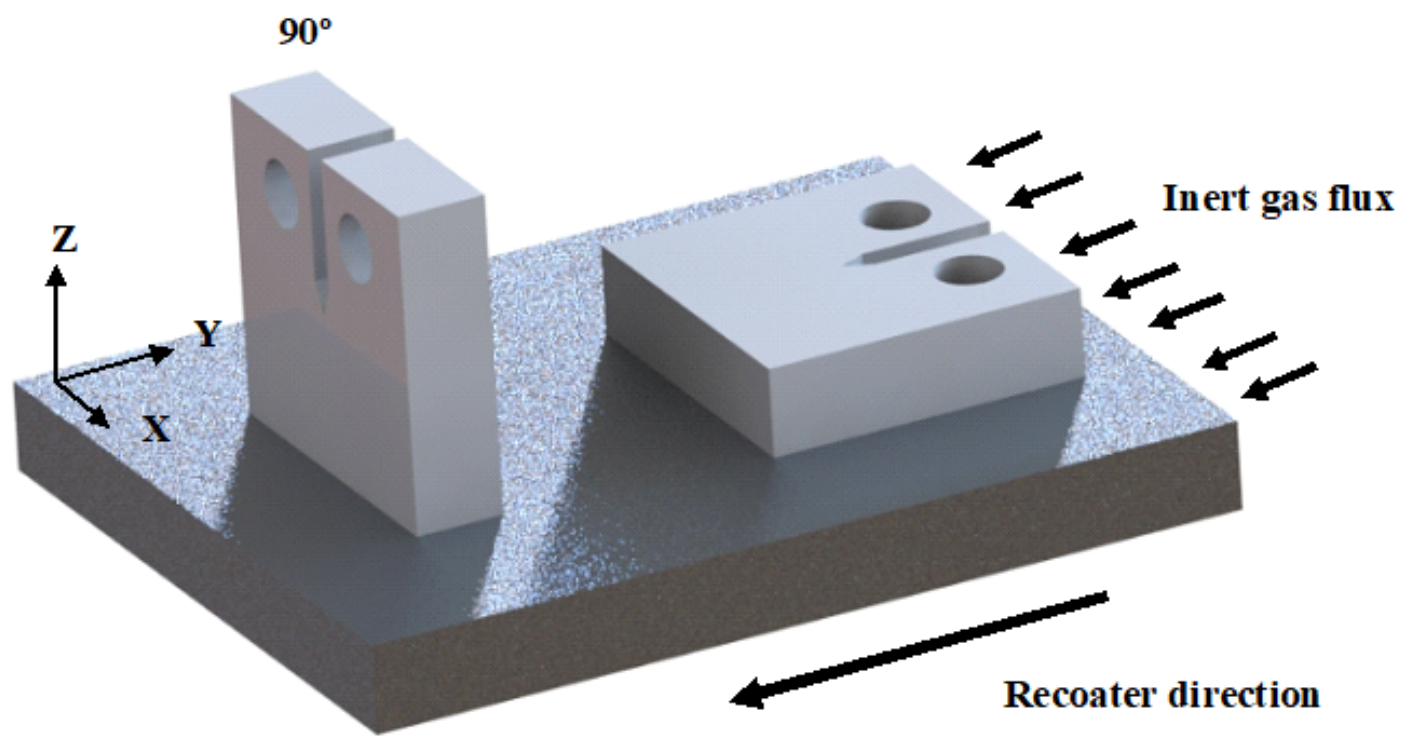

Figure 2

(a) Double shear stress specimen ASTM 769 along XY and Z direction (b) Fractural toughness specimen ASTM 399 along $X Y$ and $Z$ direction. 

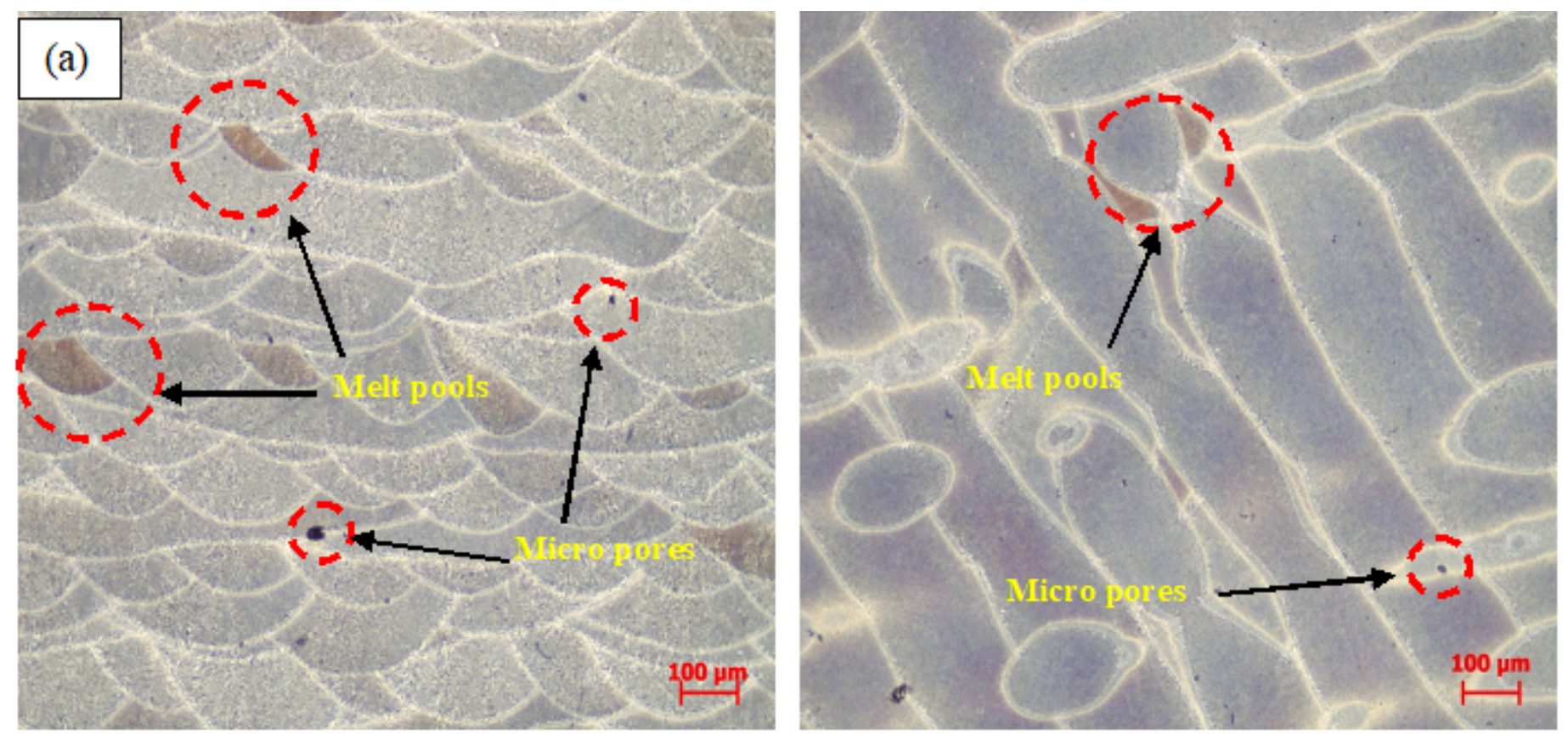

Figure 3

Optical Micrograph image of the AlSi10Mg samples (a) Z direction and (b) XY direction
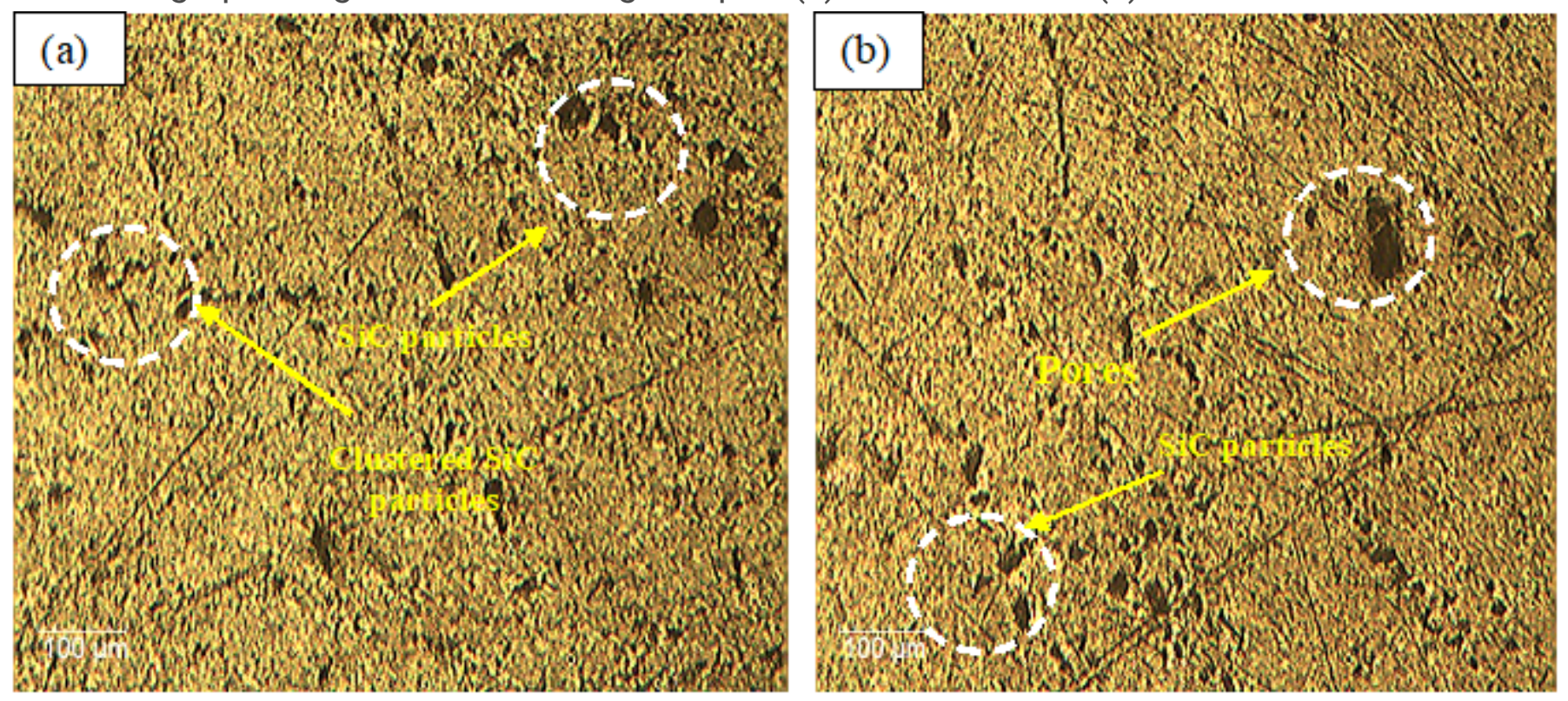

\section{Figure 4}

Optical micrograph image of the Al-SiC $10 \%$ at (a) centre and (b) outer [22] 

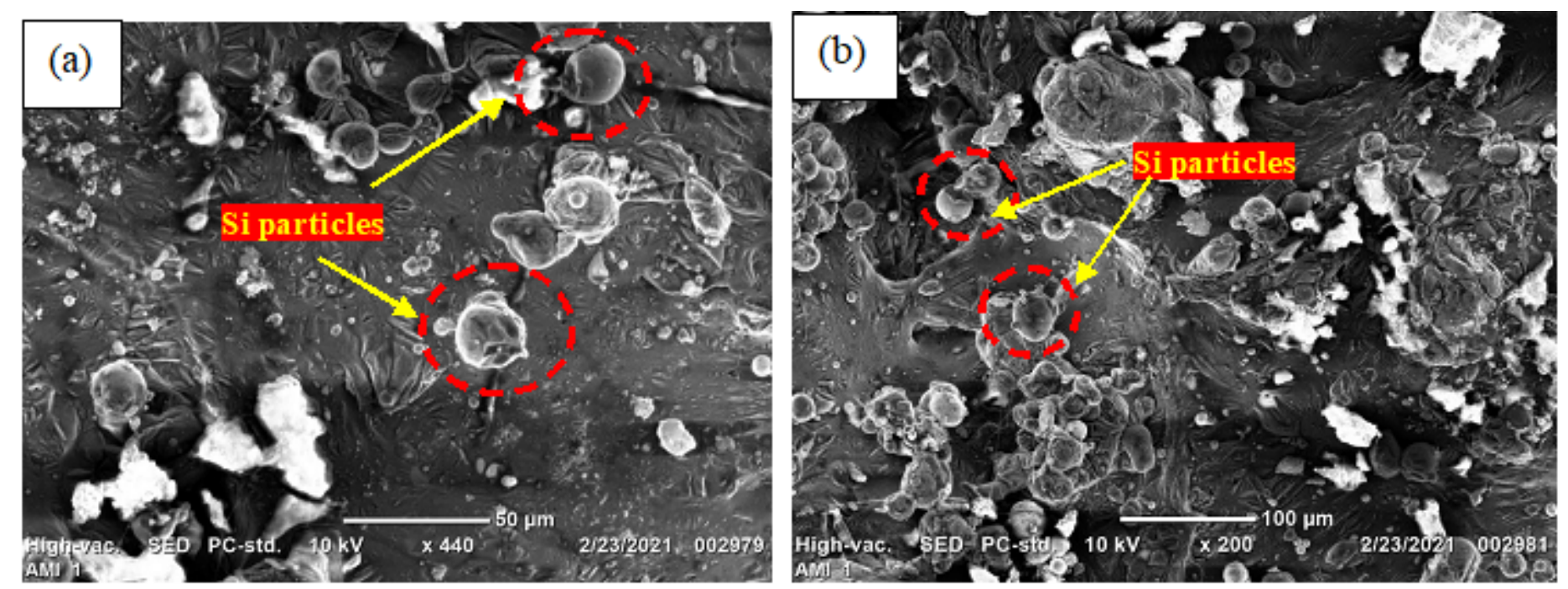

\section{Figure 5}

Scanning Electron Microscope image of the AlSi10Mg at (a) $50 \mu \mathrm{m}$ and (b) $100 \mu \mathrm{m}$
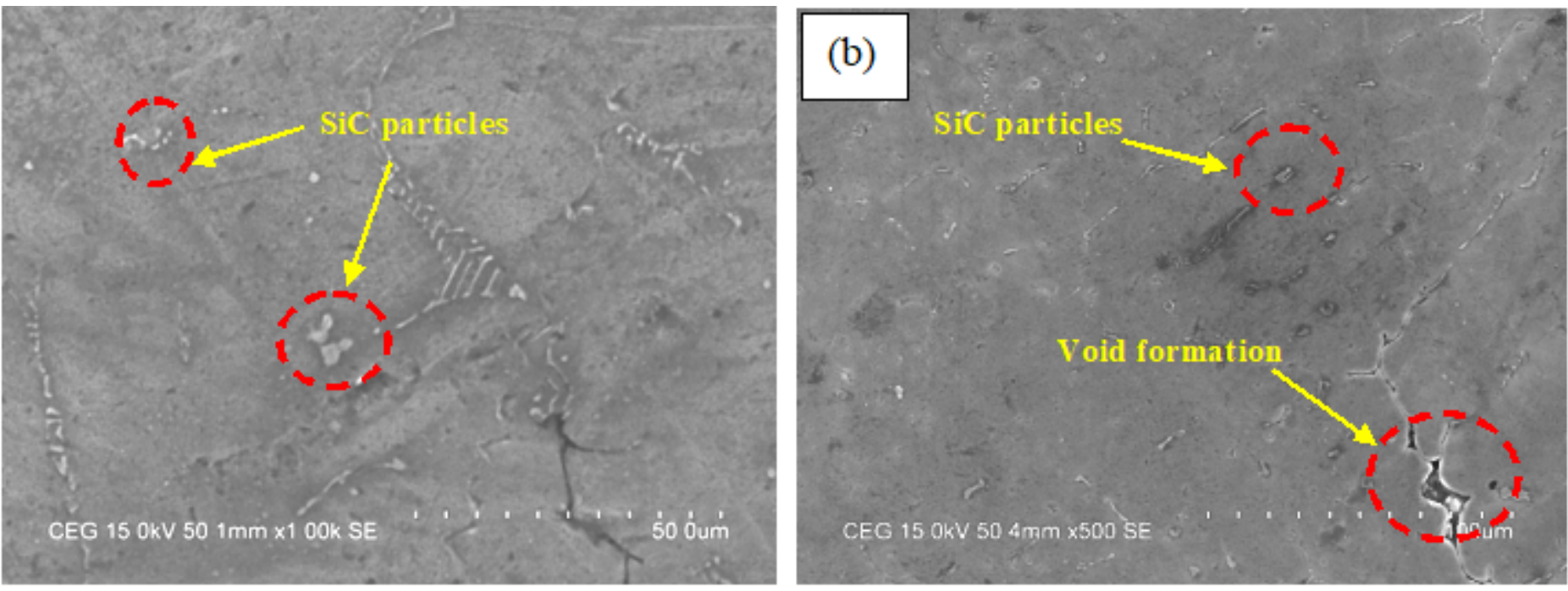

\section{Figure 6}

Scanning Electron Microscope image of the Al-SiC $10 \%$ at (a) $50 \mu \mathrm{m}$ and (b) $100 \mu \mathrm{m}$ [22] 


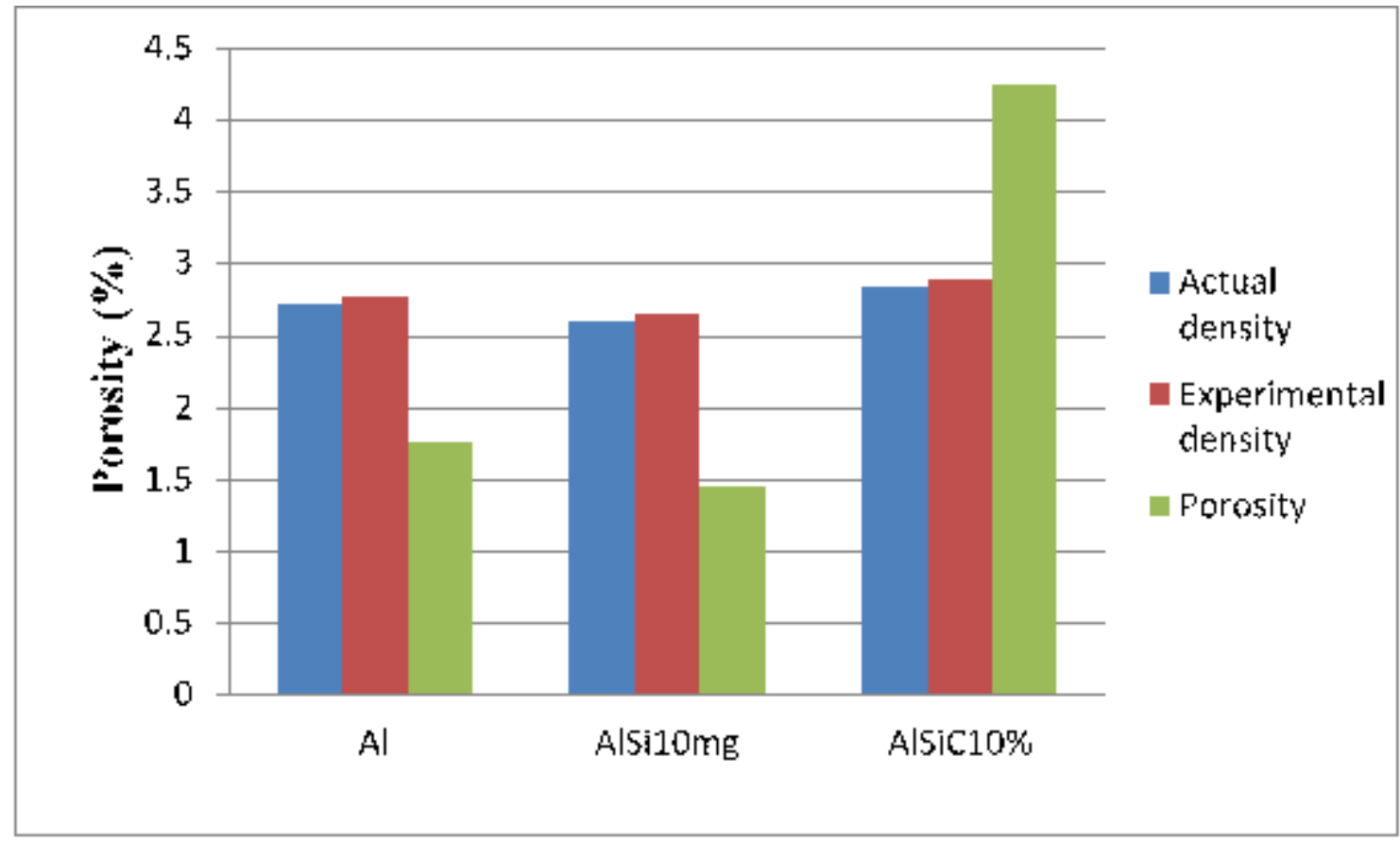

Figure 7

Comparison of porosity \% and density between the AM and SC samples.

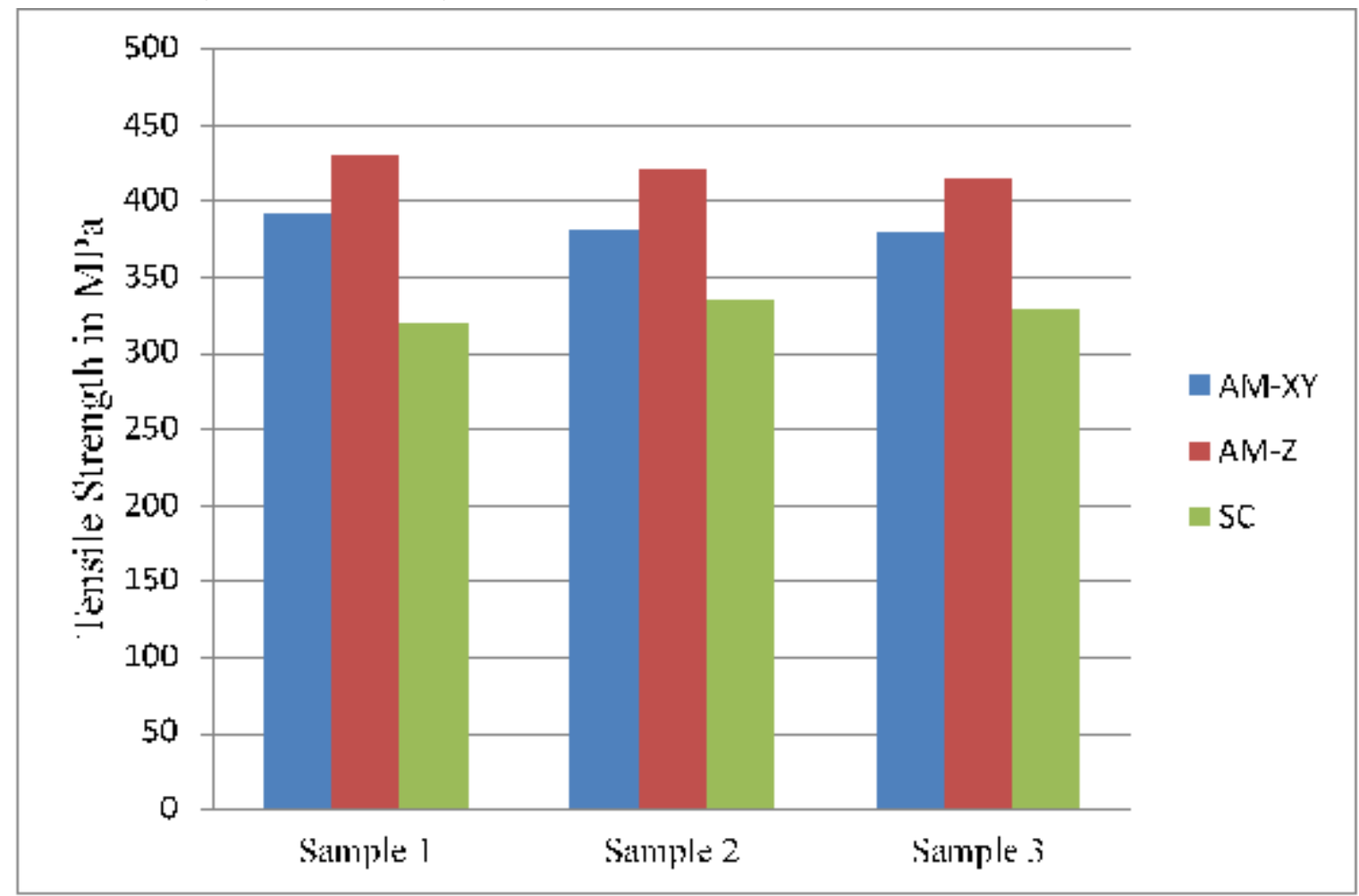

Figure 8

Comparison of tensile strength between the AM and SC samples 


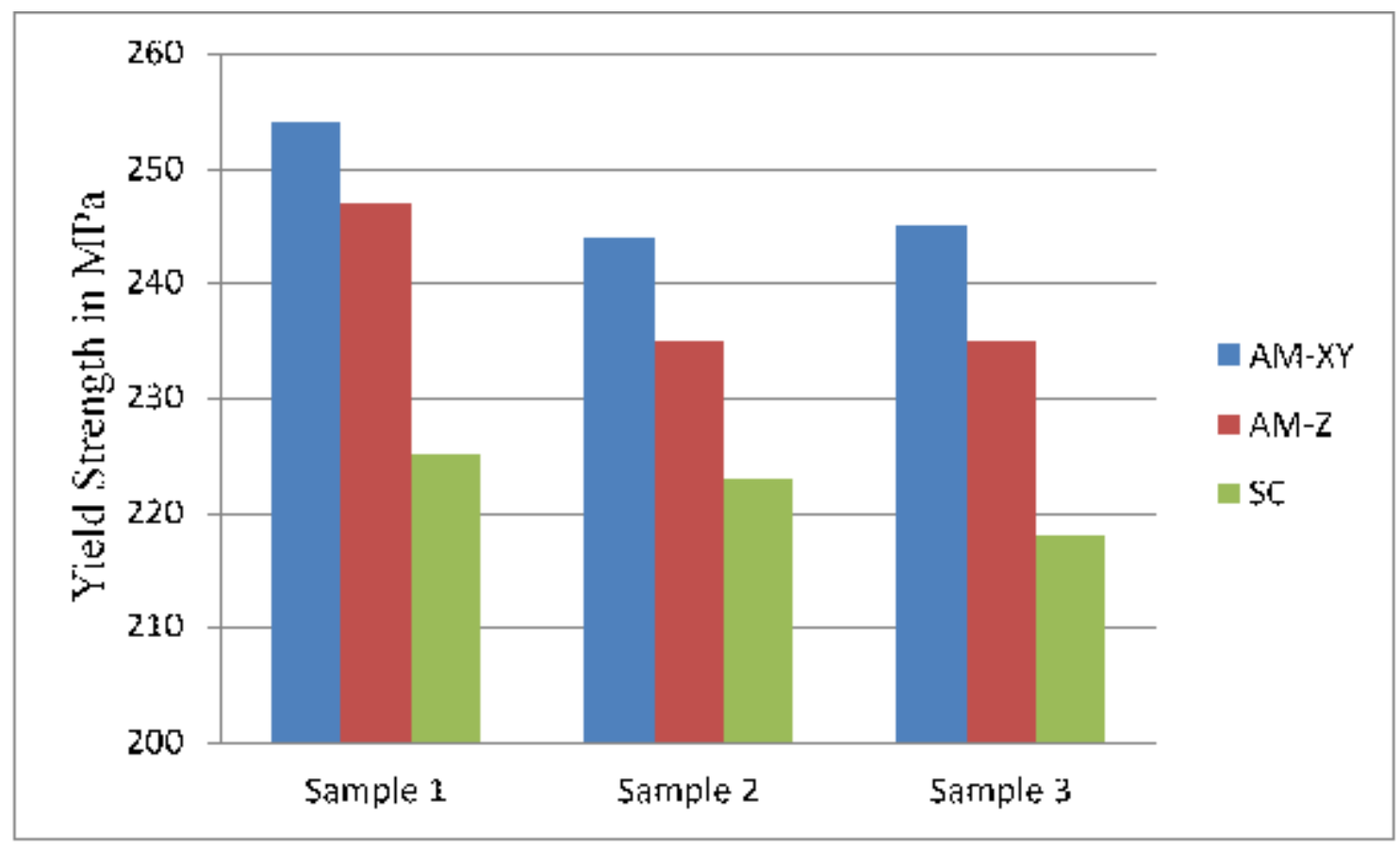

Figure 9

Comparison of Yield strength between the AM and SC samples.

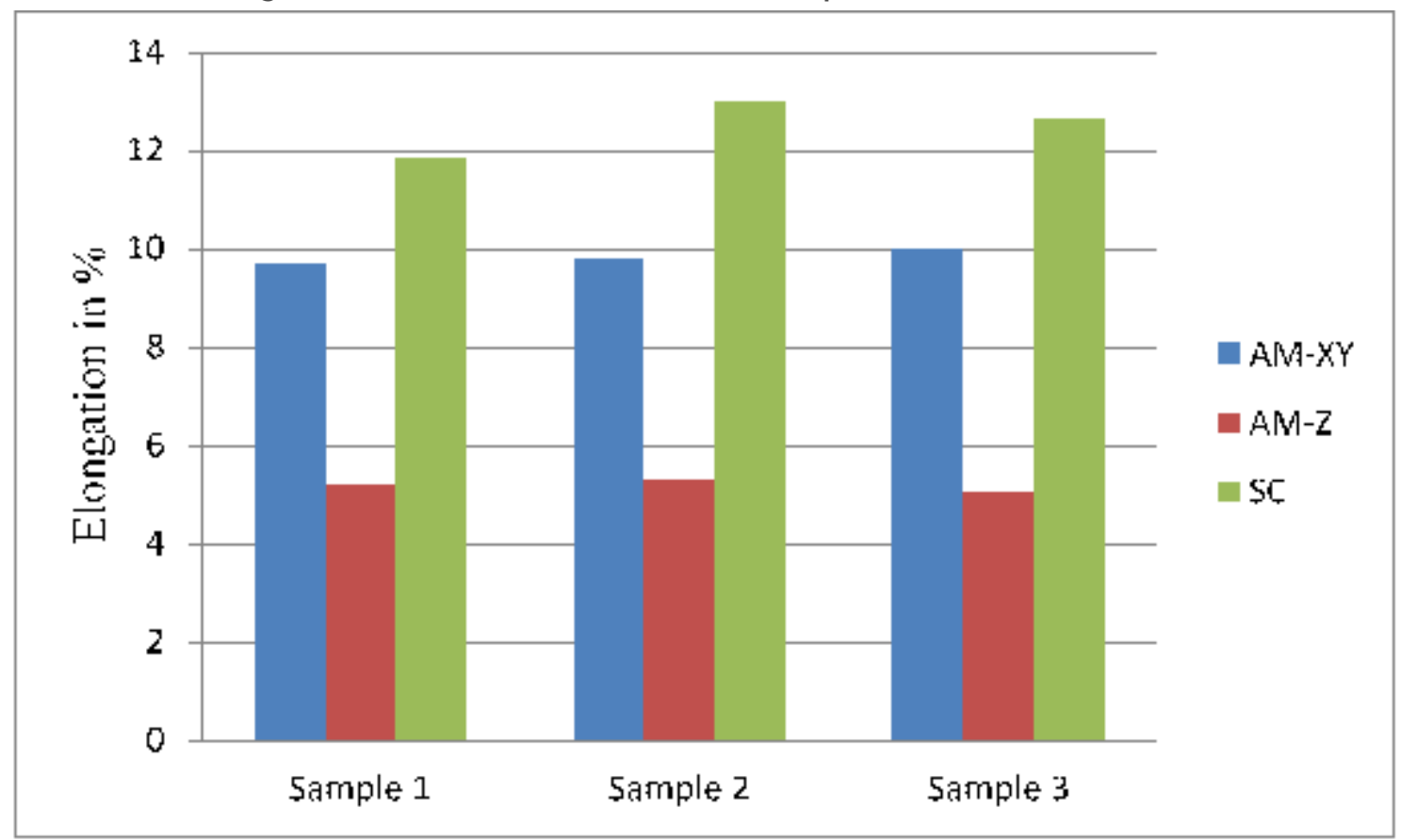

Figure 10

Comparison of elongation\% between the AM and SC samples. 


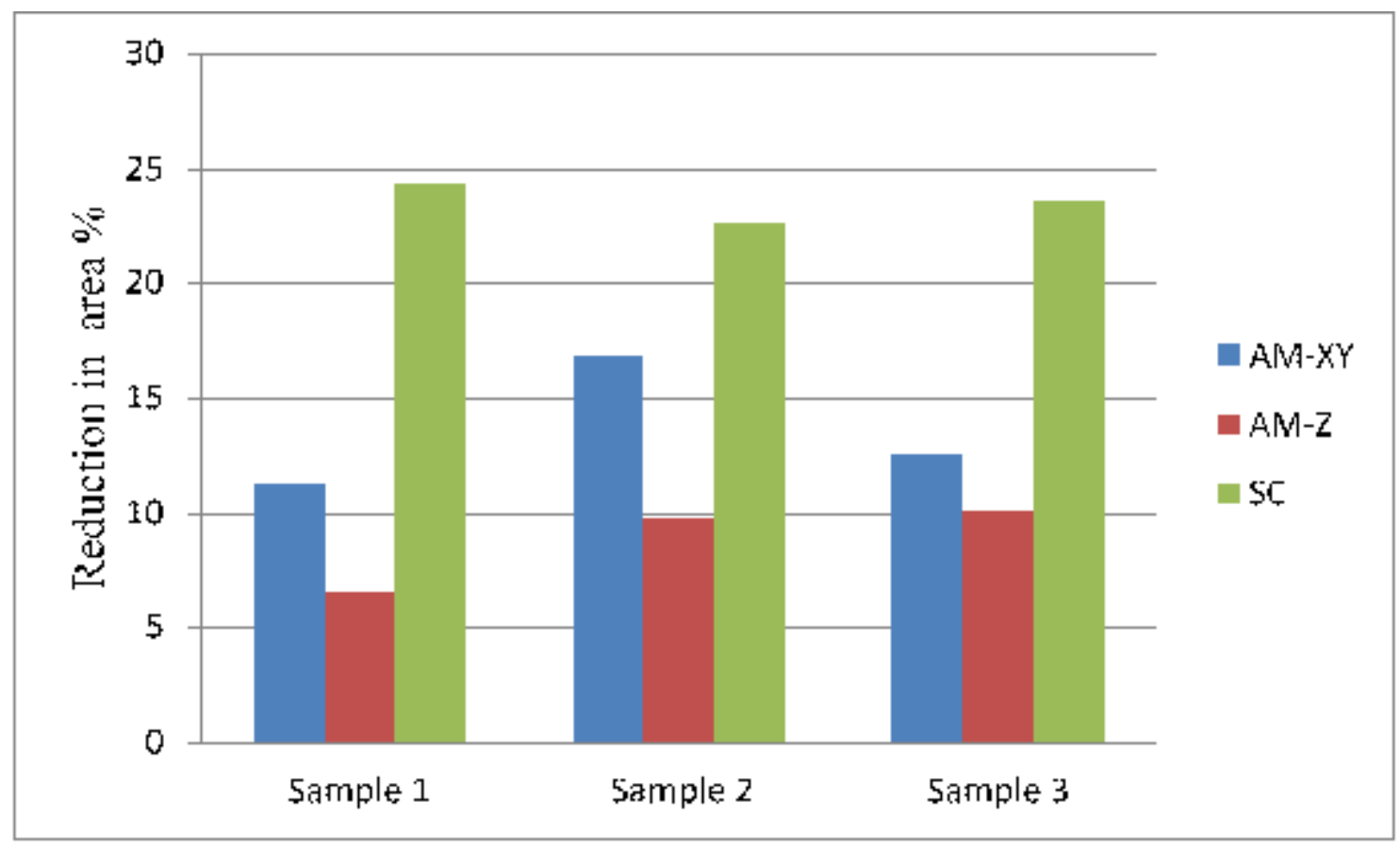

Figure 11

Comparison of reduction in area \% between the AM and SC samples.

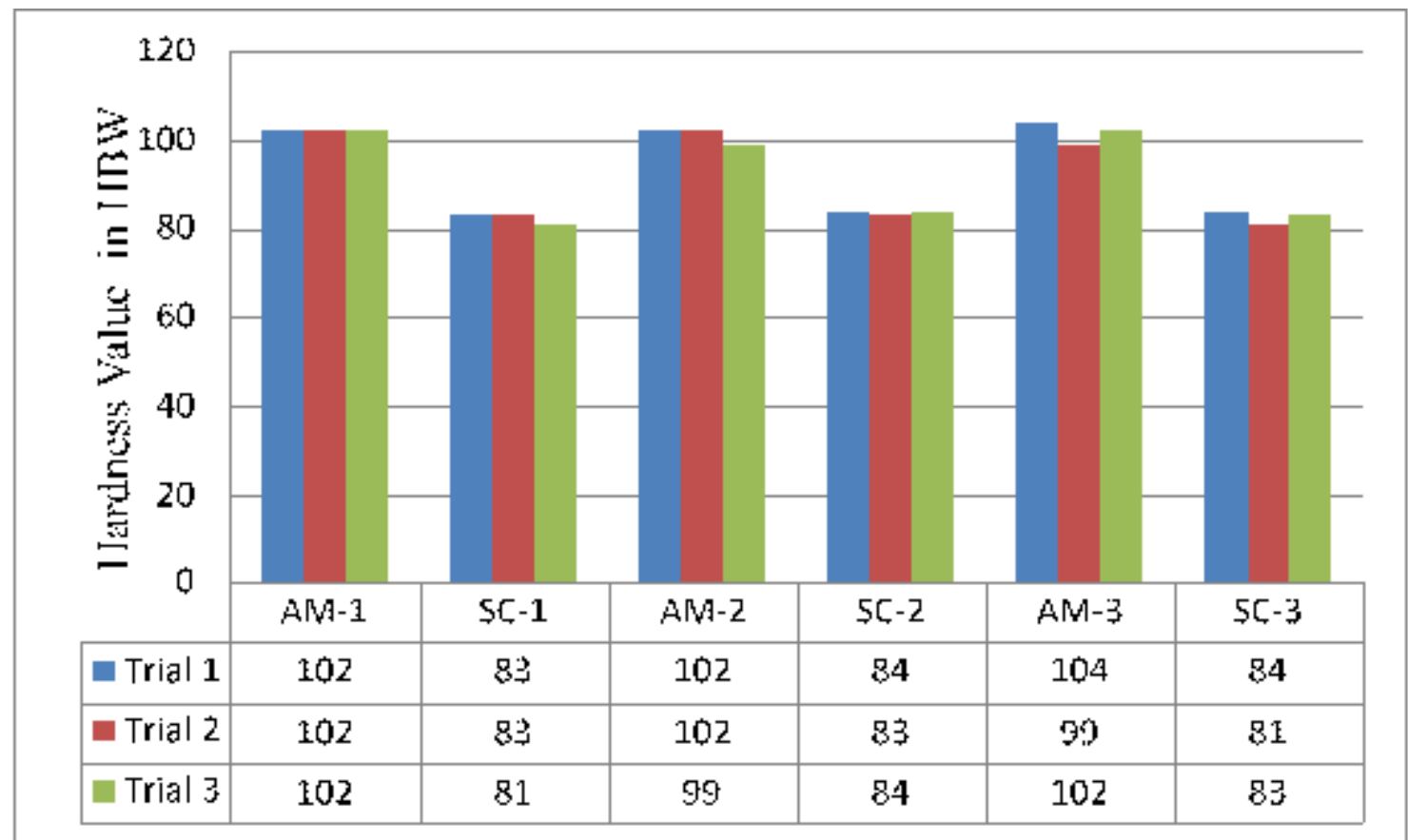

Figure 12

Comparison of hardness values between the AM and SC samples. 


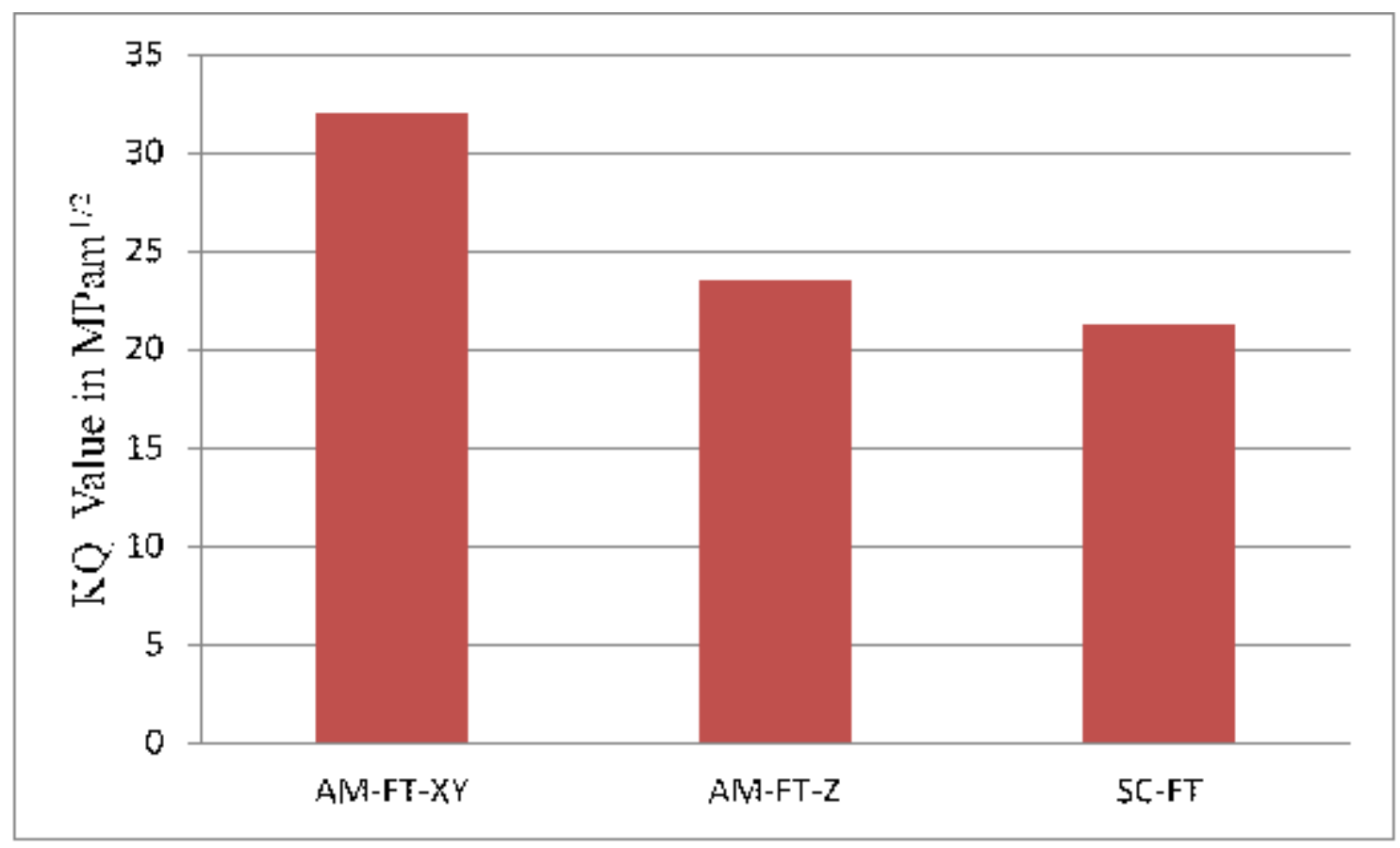

Figure 13

Comparison of fracture toughness between the AM and SC samples.

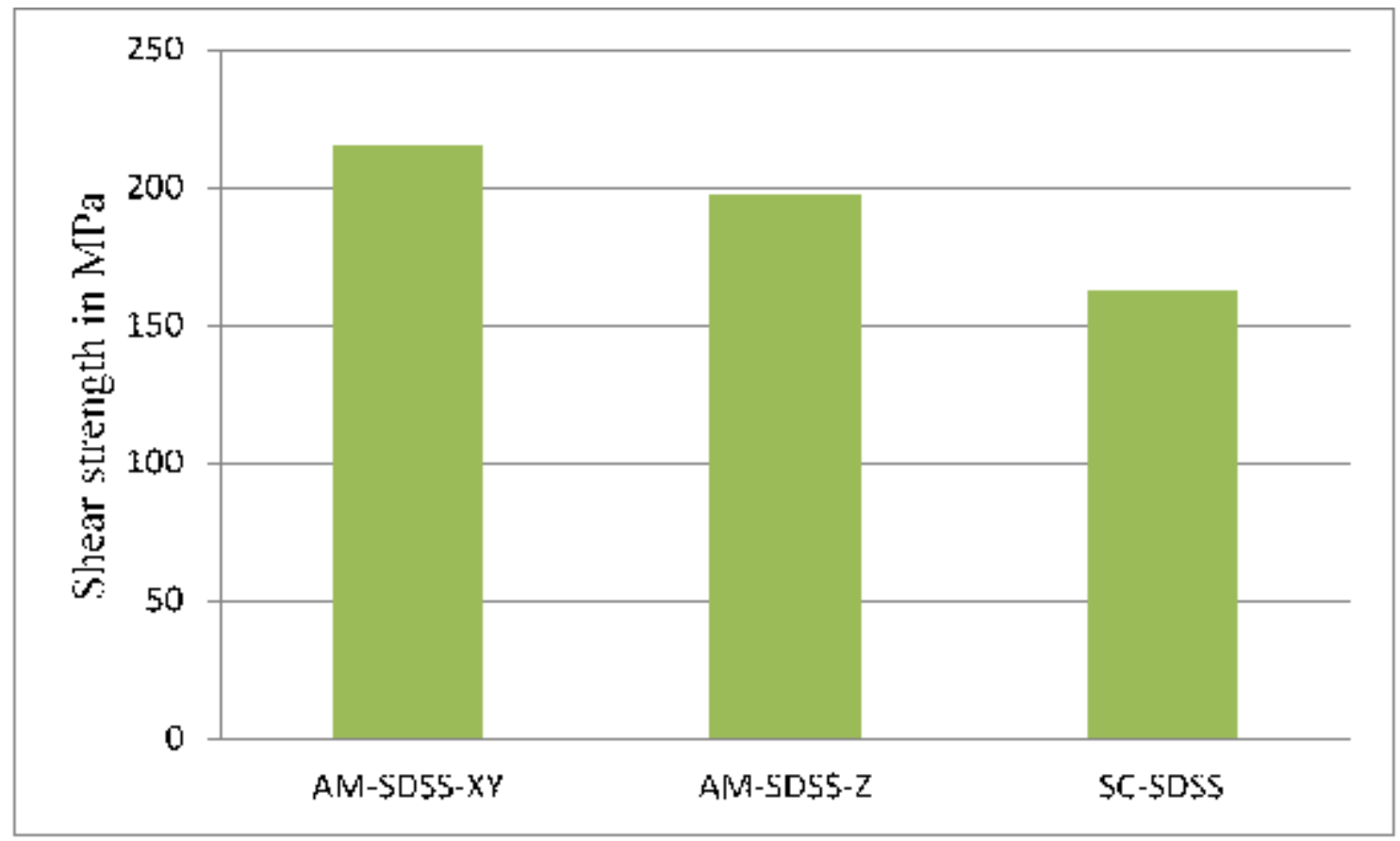

Figure 14

Comparison of shear strength between the AM and SC samples. 